Hlavac, J., \& Saunders, B. (2021). Simulating the context of interpreter-mediated social work interactions via interprofessional education. Linguistica Antverpiensia, New Series: Themes in Translation Studies, 20, 186-208.

\title{
Simulating the context of interpreter-mediated social work interactions via interprofessional education
}

\author{
Jim Hlavac \\ Monash University \\ Jim.Hlavac@monash.edu \\ https://orcid.org/0000-0002-4998-9273 \\ Bernadette Saunders \\ Monash University \\ Bernadette.Saunders@monash.edu \\ https://orcid.org/0000-0003-3830-9874
}

\begin{abstract}
Interpreters and social workers frequently work together. They share some common goals and there is some similarity between the ethical guidelines that both professions follow. Despite this, interpreter-mediated social work encounters are rarely described, especially from the perspective of interpreting studies. Even more infrequent are studies that focus on trainee interpreters' and social workers' engagement in interprofessional education (IPE). Details of the design and delivery of IPE training sessions for interpreting and social work students, at Monash University from May 2017 to May 2019, are provided. The sessions featured two role-plays that simulated typical interactions in which interpreters and social workers work together. To assess the effectiveness of the IPE training in meeting both general and specific learning outcomes, three research questions were posed and the responses are reported in this article. The questions relate to the reported usefulness of role-plays in enabling the acquisition of desirable skills and knowledge; an increase in the level of knowledge of the other professional group, one's own group and the perceived benefits for service-users; and the usefulness of pre- and post-interactional activities, such as briefing and debriefing. Responses to questionnaires were received from 218 of the 442 participating students. On a Likert scale with five gradings the average levels of agreement regarding the usefulness of role-plays are high, as are the levels of agreement about increases in knowledge of the other professional group and those of the students' own professional group. The student informants reported that the skills they gained are likely to be beneficial to clients and patients with limited English proficiency. The trainees' responses to their pre- and postinteractional interactions show that both groups registered a high level of agreement that briefings and debriefings are useful.
\end{abstract}

Keywords: interpreter pedagogy, interprofessional education, social work pedagogy, interpreter-mediated social work interactions, public service interpreting 
Hlavac, J., \& Saunders, B. (2021). Simulating the context of interpreter-mediated social work interactions via interprofessional education. Linguistica Antverpiensia, New Series: Themes in Translation Studies, 20, 186-208.

\section{Introduction}

Interpreters and social workers have much in common - not least the fact that they find themselves working with each other in a variety of contexts, from employment to child protection, and from housing to correctional facilities. How well they work with each other may depend on a host of issues, including:

- their general knowledge of the other profession and of the way that those from the other professional group work;

- their awareness of social work practice and the manner in which a social welfare interaction is structured;

- awareness of the way an interpreter-mediated interaction is different from a monolingual one;

- the ability to draw on strategies that enable social workers and interpreters to inform each other at a situational level how they will each work together;

- where this knowledge is not brought to their interactions by either or both parties, the extent to which both groups see themselves as being able to perform their duties without knowing about the other group; and

- whether they see collaborative practice as a means of performing their duties.

This article considers the ways in which interprofessional collaboration between interpreters and social workers can be developed via pre-qualification training sessions that feature learners from both disciplines in the role of protagonists with whom members of the other group may later work.

Examining the effectiveness of interprofessional education (IPE) sessions in developing trainee professionals' capacity to work with other trainee professionals, this article responds to the following research questions:

1. What are interpreting and social work students' views on the usefulness of role-plays as a main component of IPE sessions?

2. What do interpreting and social work students reveal about their:

- knowledge of the other professional group;

- knowledge of their own professional group; and

- beliefs that skills acquired in IPE will benefit service users with limited English proficiency (LEP)?

3. Having participated in an IPE session, do interpreting and social work students identify preinteractional and post-interactional activities that are useful in developing interprofessional competence?

IPE is presented and discussed in section 2, together with a discussion of the fields of interpreting and social work and the frequency of these professionals' interactions with each other. Studies from both disciplinary areas are drawn on that focus on interactions featuring 
Hlavac, J., \& Saunders, B. (2021). Simulating the context of interpreter-mediated social work interactions via interprofessional education. Linguistica Antverpiensia, New Series: Themes in Translation Studies, 20, 186-208.

professionals from the other group. In these, we highlight examples considered to be good practice and also less than optimal practice. The structure of the co-designed and co-taught IPE sessions is presented in section 3, and the methodology employed to gain a data sample, together with information on the size and features of the sample, are outlined in section 4. Informants' responses are presented and discussed in section 5, and section 6 reveals our findings in relation to the three research questions, and our conclusions. Examples of the instructions given to interpreting and social work students in preparation or the IPE session are given in the appendices, which contain the preparatory instructions for the IPE sessions provided to the interpreting and social work students.

\section{Interprofessional education, interpreting, social work and interpreter- mediated social work interactions}

IPE refers to learners from one profession learning about the work of another profession in a joint interaction. The objective is to enable both professions to acquire the skills, knowledge and attitudes that encourage them to work more collaboratively and effectively. This benefits not only the members of both professional groups, but also third parties. For example, in the domain of social welfare these would be service users (Buring et al., 2009). IPE can be structured either as a post-qualification activity for practising professionals or as a prequalification activity for trainees. This article focuses on the latter.

IPE in pre-qualification programmes commonly features simulated activities and role-plays, as trainees do not yet have the required certification or registration to seek professional employment. Role-plays and simulated activities are teaching tools commonly used in the education and training of both interpreters and social work students. Consequently, the use of role-plays and simulated activities in IPE is a learning technique familiar to trainees that is then applied in an unfamiliar environment. It should be noted that apart from brief inductions into the contemporary practice of each professional group at the start of the IPE sessions (see section 3) and prescribed readings on interpreter-mediated social work interactions (e.g., Ozolins, 2013; Sawrikar, 2015), role-plays are the main activity employed to enable trainees to acquire, in an aspirational sense, "knowledge, skills and attitudes that result in interprofessional team behaviors and competence" (Buring et al., 2009, p. 2). Therefore, trainees' engagement with and responses to IPE are strongly based on role-plays as the main learning activity employed. No other "learning by doing" activity is included in the IPE sessions, and the trainees do not have a point of comparison against which to evaluate the usefulness of the role-plays in achieving the IPE learning outcomes.

Furthermore, IPE exercises simulate interactions in which professionals from both groups will frequently find themselves. These exercises are designed to set up, as closely as possible, authentic and realistic interactions that are likely to occur in their professional careers.

\subsection{Contexts of interpreting and social work: differences and similarities}

Both interpreting and social work are service professions that require high-level communication and interactional skills, and both focus on others' verbal or signed behaviour. In interpreting, this alignment results in interpreters' fully understanding and fully replicating 
Hlavac, J., \& Saunders, B. (2021). Simulating the context of interpreter-mediated social work interactions via interprofessional education. Linguistica Antverpiensia, New Series: Themes in Translation Studies, 20, 186-208.

the content of what is being said (the "locutionary act") together with the intention behind the way it is said (the "illocutionary act"). In social work, this alignment allows social workers to understand others' situations, needs and capabilities, and also to enable them to consider various options or actions to adopt in response. Notably, the outcome when interpreters and social workers work with others is that those with whom they work are enabled to then engage independently in constructive activities beyond those of the interpreter-mediated or social worker-mediated interaction.

Interpreting and social work both arose as professions in the twentieth century, albeit in different circumstances. In the first half of the twentieth century, the "founders" of interpreting worked mostly in diplomacy, international affairs or business settings. It was not until social services became established in the post-Second World War era (after the establishment of the "welfare state" in some countries) that professional interpreting started to be practised on a large scale in settings such as social welfare. Since the 1970s and the emergence of public service interpreting, a substantial volume of interpreters' work in many countries has entailed working with social workers who engage with people with whom they do not have a common language and also with people who are not able to communicate functionally with a social worker.

In the English-speaking world at least, social work emerged as a profession in the early twentieth century, around the time of the Great Depression in the 1920s. However, its establishment as a more well-recognised profession, despite the diversity in the way it is practised, did not occur until the late 1960s and the early 1970s. That was a time when policies related to equity of access led to an expansion of government-funded services in the area of social welfare; the need for social workers to enable service provision was a natural outcome of that shift (Stuart, 2013). Social work is practised in many settings and ranges from direct practice with adults and children through to research and policy work.

Consequently, interpreting as a profession - or at least public service interpreting - now commonly intersects directly with social work practice. Interpreters frequently work with social workers and a variety of clients who access social welfare services. The characteristics of these interactions include not only the allophone interlocutors who communicate with each other via an interpreter, but individuals of diverse socio-economic backgrounds, educational levels, classes, employment opportunities, physical and mental health, and domestic living situations. In addition, many others contribute to shaping not only the theme and the context of the interpreter-mediated interaction but also its dynamics, its purpose and the interlocutors' forms of communication. As public service interpreting began to attract the attention of both researchers and trainers of interpreting, a "social turn" in interpreting studies evolved where social categories, such as class, gender and status, began to feature as categories or variables in research streams (Pöchhacker, 2006).

Both public service interpreting and social work have a legacy of activism and agency for social change that have influenced many interpreters' and social workers' perceptions of themselves and their professions, and the ways in which outsiders view them (Abramovitz, 1998; Bancroft, 2015). Significantly, Banks (2004, p. 5) observes that some people label the social care and welfare professions as "semi" or "quasi" professions. Tipton (2016) similarly 
Hlavac, J., \& Saunders, B. (2021). Simulating the context of interpreter-mediated social work interactions via interprofessional education. Linguistica Antverpiensia, New Series: Themes in Translation Studies, 20, 186-208.

observes that the same terms are used in relation to public service interpreting on the basis of its similar roots in the voluntary and charity sectors. With these shared features in mind, Tipton (2016) identifies similarities between the two professions. She presents qualitative, self-reported data from both interpreters and social workers in her investigation of "occupational intercultures" that emerge when an interpreter works with a social worker and, in addition to reflexive approaches to practice, she describes the impact of interpreter mediation in the way that social workers' can effect change and agency (Tipton, 2016, p. 463). While both interpreters and social workers can be seen as agents of change, Tipton (2016) alerts us to the different outcomes that each group can achieve:

Social workers are lead instigators of change in a technical and rational sense, whereas interpreters are primarily viewed as change agents by virtue of their capacity to potentialise and facilitate change; this involves technical expertise or cultural capital, but of a different type to the social worker's (p. 469).

The notion of "occupational interculture" that exists when interpreters and social workers work together is a theoretical one. However, similarities can be observed in each profession's procedural requirements, ethical principles, personal safety and integrity, and risk-aversion measures. Acknowledgement and recognition of the need to work effectively with the other group has often resulted in profession-specific instructions or guidelines to achieve this goal. As far back as the 1970s in Australia, guidelines were drawn up advising social workers how to work with interpreters - for example, Baker and Briggs (1975) - and they have continued to appear regularly ever since - for example, Jones (1985), Frey et al. (1990), CMY (2011) and DHHS (2018).

The existence of these guidelines produced over a 40-year period suggests, first, that social workers' contact with interpreters has been long-standing and, second, that interpretermediated interactions can and should attract some attention. Third, the production of advisory guidelines suggests that there is a "knowledge gap" among some, if not many, social workers. Fourth, it informs us that there are practices and protocols that can be followed which enable social workers to communicate and work effectively with service users who have limited English proficiency. In the context of IPE, these guidelines can be invoked as evidence of the need for social workers to know how to work with interpreters. In a concrete sense, guideline documents strongly recommend a pre-interactional briefing between social worker and interpreter; and most also mention a debriefing as a recommended or aspirational feature. Sections 2.3 to 2.5 are devoted to a discussion of how each group can work with the other.

\subsection{Determining the how often interpreters and social workers work with each other}

Determining how frequently each group works with the other is challenging. Regarding the way interpreters work with social workers, a major translation and interpreting agency in Australia notes that $42.3 \%$ of its 410,017 requests for interpreting services in one year were for the area of welfare (Hlavac et al., 2018, p. 77). In 2019 in Australia, a survey of 2,530 interpreters revealed that social welfare was the second most frequent area of work. Almost $48 \%$ reported that they "often" worked in this field, while a further $43 \%$ reported that they 
Hlavac, J., \& Saunders, B. (2021). Simulating the context of interpreter-mediated social work interactions via interprofessional education. Linguistica Antverpiensia, New Series: Themes in Translation Studies, 20, 186-208.

"sometimes" worked in this field (Tobias et al., 2020, p. 14). These figures suggest that many interpreters work regularly with social workers, at least in countries with extensive social welfare services and with an infrastructure that supports public service interpreting (Lannoy \& Van Gucht, 2006, p. 193).

\subsection{Interpreter-mediated social welfare interactions: perspectives from interpreting studies}

There are comparatively few published studies on interpreters working with social workers from an interpreting studies perspective. Books on public service interpreting, such as Hale (2007) or Corsellis (2008), focus mainly on healthcare and legal settings. Pöllabauer's (2012) study is one of the few to be based on an interpreter-mediated social work encounter, but its focus is mainly on an application of gate-keeping theory to analyse the interlingual conventions of a lay and untrained interpreter rather than the social welfare context itself.

Tipton and Furmanek (2016) provide the most broadly focused study of social work encounters from the perspective of interpreting studies. These authors present content knowledge on professional and ethical principles, that is, the "social worker roles and standards" (in the UK) which contain six roles and 20 standards that inform social work practice. Among these roles and standards is "practice social work in multidisciplinary settings", that is, working with other professionals such as interpreters (Tipton \& Furmanek 2016, p. 207).

Another area of content knowledge is that of "cultural competence" in social work, based on Ben-Ari and Strier's (2010) and Van der Haar's (2007) work in this area. They discuss examples of some social workers' conceptualising culture as both a "descriptive category (to describe the service user's content) and an explanatory category or as an 'all-determining factor and explanation of the client's problem'" (Tipton \& Furmanek, 2016, p. 209; original brackets and punctuation). This second explanatory category of culture as an "all-determining factor" is one that has been criticised in some guidelines released by interpreters advising healthcare professionals which could also apply to social work situations:

Under the normal circumstances of general health interpreting, you should not be asking interpreters to give information about the patient's culture, unless communication has broken down. The importance of culture can be over-emphasised. All patients have different personalities, temperaments and life experience, and may vary considerably in the way they manifest their cultural background. However, professional interpreters know that language expression does not happen in isolation from customs and beliefs, especially in the health area (AUSIT, 2006, p. 6).

Tipton and Furmanek (2016, p. 209) would appear to be largely in agreement with the above statement and refer to instances where "social workers could mistakenly equate cultural characteristics with deficiencies as opposed to cultural difference". They do not, however, "suggest that interpreters have a part to play in unravelling such matters" (Tipton \& Furmanek, 2016, p. 209) but call on the interpreter to acknowledge the service provider's and the LEP client's cultural positioning and to recommend considering these before making a decision whether or not to intervene. 
Hlavac, J., \& Saunders, B. (2021). Simulating the context of interpreter-mediated social work interactions via interprofessional education. Linguistica Antverpiensia, New Series: Themes in Translation Studies, 20, 186-208.

Today, at least in Australia, accreditation standards applying to university courses in social work require the acquisition of cultural competence, including recognition of service users' cultural and social backgrounds. The Australian Social Work Education and Accreditation Standards (AASW, 2019) include practice standards such as "culturally responsive and inclusive practice", requiring the skills to "work with interpreters to maximize service users' rights and involvement" (AASW, 2019, p. 20); and practice standards related to "culture, identity and discrimination" requiring social workers to be skilled in "culturally safe and sensitive practice [including] consideration of ... the use of interpreters ... to minimize language barriers" (AASW, 2019, p. 27). Unfortunately, some social workers may still anticipate that an interpreter will provide this information:

in practice, the pressures of time and casework volume may be such that reliance on an interpreter can be seen as a means to compensate for the social worker's lack of research time (Tipton \& Furmanek, 2016, p. 209).

These issues of social workers' notions of culture, the ways in which different groups may conceptualise a social work interaction, protocols for interpreter interventions, and further issues, are best raised in a briefing and revisited in a debriefing.

\subsection{Interpreter-mediated social welfare interactions: social work perspectives}

There are many studies in which practitioners or researchers in social work explore interpreter-mediated interactions. Early studies include Baker and Briggs (1975) and Glasser (1983). Freed's (1998) observation of social worker-client mental health interactions still applies to social work practice today:

...[b]ecause the art of social work interviewing requires rapport, an empathetic interchange and an emotional connection, the interpreter must have the capacity to act exactly as the interviewer acts - express the same feelings, use the same intonations to the extent possible in another language, and through verbal and nonverbal means convey what the interviewer expresses on several levels (p. 316).

Freed (1988) also strongly recommends a briefing in which operational and logistical features can be agreed, such as the social worker's opening the interaction with a client, introducing the interpreter and explaining their presence and role, and giving assurances of confidentiality to the client. The value of a debriefing is also suggested as a means of consolidating and enhancing interprofessional collaboration:

After each interview, the interpreter and interviewer reviewed the content to allow clarifications, deeper understanding, descriptions of cultural dictates, and explanations of specific behaviour .... The interchanges were educational for both and increasingly led to effective teamwork (Freed, 1988, p. 319).

In a similar vein, Turner (1990, pp. 128-129) calls for both social work and interpreting researchers to "write about their experiences ... so that we can better tap the rich accumulation of wisdom that exists among our colleagues", and suggests that "it would be useful if at least some schools of social work included this material in their curricula". This last point where trainees in one discipline learn about the other can be a precursor exercise to 
Hlavac, J., \& Saunders, B. (2021). Simulating the context of interpreter-mediated social work interactions via interprofessional education. Linguistica Antverpiensia, New Series: Themes in Translation Studies, 20, 186-208.

IPE. Dubus (2015) reports on briefing and debriefing as being important features in the building of a professional relationship between counsellor and interpreter that could almost be described as supervisory.

The social work literature clearly recognizes that an interaction with service users mediated via an interpreter alters the social worker-client relationship. In some cases, an interpreter's presence may have a negative impact. Along with Pöllabauer's (2012) finding that a lay interpreter may be selective and exclusionary in providing interlingual transfer to and from a social worker, social work researchers have identified several perceived shortcomings. Humphreys et al. (1999) describe social workers' uncertainty about the role of the interpreter and, similarly, interpreters' uncertainty about how to work with social workers. Tribe and Raval (2002) and Brämberg and Sandman (2012) voice concerns about confidentiality. Tribe and Morrissey (2004) and Westlake and Jones (2018) observe that social workers can feel thwarted in their attempts to develop rapport with a client who requires an interpreter.

\subsection{Interpreter-mediated social welfare interactions: service users' perspectives}

With some notable exceptions, including Humphreys et al. (1999) and Berthold and Fischman (2014), studies rarely solicit service users' perspectives. One study, with a dual focus, comes from Sawrikar (2015), who interviewed 29 families with LEP and 17 child protection case workers. From a social work perspective, she located examples of good practice and ineffective practice in her data, where 'practice' refers to either the interpreter's or the social worker's performance.

Sawrikar (2015) identifies interpreters' lack of familiarity with child protection matters, services and terminology as a barrier to good practice. Chand (2005) similarly called for interpreters working in social welfare to acquire knowledge about social work practice and institutional structures. This point also applies to other domains in which interpreters work. However, to what extent ought interpreters (and trainees) be expected to acquire content knowledge of all of these domains in order to optimise their interpreting performance? Part of the answer to this question lies in increasing interpreter and social work trainees' knowledge of how to work with each other.

A case worker in the quotation below proposes that a pre-interaction briefing before a client interaction can be a preventive strategy which can ensure that less than optimal practices are avoided:

I think we should be saying prior to them [the interpreter] walking into a meeting, "this is what we are going to be discussing today", so it's not a shock ... especially if we were going to be talking about sexual abuse... because you don't know about their background, their experience either, and how that might impact on them communicating with the family (Sawrikar, 2015, p. 402; original punctuation and brackets).

The case worker is referring to a situation familiar to many interpreters who do not ask for a briefing or who are refused one when a briefing is requested. This can affect the interpreter's ability to understand what is being said, to what purpose, and to whom, often because they do not know who they will be interpreting to and from and what their role and relationship 
Hlavac, J., \& Saunders, B. (2021). Simulating the context of interpreter-mediated social work interactions via interprofessional education. Linguistica Antverpiensia, New Series: Themes in Translation Studies, 20, 186-208.

are to one another. The interpreter's inability to understand fully what is being said can also arise when they are not informed of the context of the situation; this can be the case especially in interactions where case workers and family members have already become familiar with one another and where they use elliptic or multi-layered speech in relation to knowledge that they have come share. The interpreter's ability to work effectively and to convey accurately what all the parties say or sign is greatly advanced by an industry-standard briefing, at least in healthcare and legal settings in Australia (VTPU, 2006; JCCD, 2017).

\section{Structure of the IPE sessions}

Both cohorts of students received pre-session readings about the other professional group's work and general information about the format and chronology of the activities. Ten days before each IPE session, all the social work students were sent a description of their roles as English-speaking parole officers or child protection workers. A description of the role of the speaker speaking a language other than English (LOTE) for each scenario was sent to those interpreting students who were allocated the role of the LOTE-speaker for that scenario. Otherwise, those interpreting students who were allocated the role of the interpreter were not supplied with such information and were informed only that they would be interpreting in a parolee-parole officer interaction or a family violence victim-child protection worker interaction. Appendix 1 contains the role descriptions for the family violence interaction.

The IPE session consisted of the following:

1. introductory address including outlines on contemporary practice in both interpreting and social work;

2. break up into groups for first role-play scenario featuring two parole officers, one parolee LEP service user and one interpreter (other students observe);

3. intragroup reflection and discussion;

4. second role-play scenario featuring two child protection workers, one family violence victim LEP service user and one interpreter (other students observe);

5. intragroup reflection and discussion; and

6. all trainees re-assemble in central auditorium for collective intergroup discussion, including a Q\&A session.

There were between eight and eleven groups of students, each consisting of two social work students taking on allocated roles, one LOTE-English interpreter and one LOTE-speaking service user, with the remaining social work students observing. Post-session activities included reflection on the role of others and on one's own practice in cohort-specific learning activities.

\section{Methodology}

A questionnaire was the methodological instrument used to collect the informants' responses to the research questions. Questionnaires are a commonly used instrument in both interpreting studies (Hale \& Napier, 2013) and social work research (Rubin \& Babbie, 2011); they are also an instrument used in other studies that elicit participants' responses in other 
Hlavac, J., \& Saunders, B. (2021). Simulating the context of interpreter-mediated social work interactions via interprofessional education. Linguistica Antverpiensia, New Series: Themes in Translation Studies, 20, 186-208.

IPE sessions for interpreting students (e.g., Krystallidou et al., 2018). Self-reported descriptive accounts of forms of change elicited from trainees are an amenable and widespread measuring instrument, but we are reminded that data gained in this way contain trainees' perceptions of (their own) change rather than actual change effected by them (Cooper et al., 2001). The questionnaire was distributed in both paper form and electronically (via Qualtrics).

Student participation in the questionnaire was voluntary (and anonymous) and those who participated responded to five questions. The participants could provide short answers of up to three lines and, in one question containing five statements, the participants responded to a five-point Likert scale. The responses to one of the short-answer questions and to four of the five statements on the Likert scale comprise the data upon which this article reports. ${ }^{1}$

The data sample consists of corpora from multiple joint IPE sessions. Responses were collected from three IPE sessions, conducted annually in May in 2017, 2018 and 2019. Collections from three consecutive years enabled us to observe whether the trainees gave recurring accounts of their acquisition of skills or knowledge from one IPE session to another. Both year and cohort are variables that we apply in the presentation of the results emanating from the first two research questions. The cohort of social work students includes students mostly from the Master of Social Work (MSW) degree and a small number of students from the third year of a Bachelor of Social Work (BSW) degree. As a proportion of those social work students who participated in the questionnaire, the number of BSW students is small: 2017 0 out of 29; $2018-14$ out of $66 ; 2019-2$ out of 80 . Their educational and skill level profile as third-year BSW students is congruent to that of the MSW students, who were all in their first or second semester. As their educational profiles are similar and congruent, we group all of the social work students under the acronym 'MSW' and we do not distinguish social work students studying in the BSW from those in the MSW. Table 1 is an overview of the number of students who took part in the IPE sessions and the number of those who participated in the survey.

Table 1. Number of students attending and participating in an evaluative survey of IPE.

\begin{tabular}{lcccccccc}
\hline & \multicolumn{2}{c}{2017} & \multicolumn{2}{c}{2018} & \multicolumn{2}{c}{2019} & \multicolumn{2}{c}{ Total } \\
\hline & Att. & Surv. & Att. & Surv. & Att. & Surv. & Att. & Surv. \\
\hline MITS & 21 & 15 & 26 & 16 & 16 & 12 & 63 & $43(68 \%)$ \\
\hline MSW & 102 & 29 & 151 & 66 & 126 & 80 & 379 & $175(46 \%)$ \\
\hline Total & 123 & 44 & 177 & 82 & 142 & 92 & 442 & $218(49 \%)$ \\
\hline
\end{tabular}

The attendance numbers and survey participant numbers are commensurate with the number of students in the respective units. For MITS, this was between 16 and 26 students. For MSW this was between 102 and 151 students. For students enrolled in these courses, attendance at the IPE sessions was compulsory. 
Hlavac, J., \& Saunders, B. (2021). Simulating the context of interpreter-mediated social work interactions via interprofessional education. Linguistica Antverpiensia, New Series: Themes in Translation Studies, 20, 186-208.

\section{Results and discussion}

As stated above, the research questions relate to the following:

- the reported usefulness of role-plays as an activity to achieve learning outcomes;

- the reported changes in participants' perceived knowledge of the other professional group;

- the reported changes in their knowledge of their own professional group;

- their perceptions of the likely benefits to LEP service users; and

- the reported usefulness of pre-interaction and post-interaction activities.

The presentation on, and the discussion of, the results relating to the first four questions are based on the responses to the Likert-scale questions. The last research question relating to pre- and post-interactional activities is addressed via data gained from short-answer responses. The Likert-scale questions contained five gradings: 1 = definitely do not agree; 2 = do not agree; 3 = not sure; 4 = agree; $=5$ strongly agree. A higher sum figure is indicative of respondents' agreement with a statement (max. highest score $=5$ ), while a lower one indicates disagreement (max. lowest score $=1$ ). Table 2 presents the informants' responses in relation to the perceived usefulness of role-plays as a means to achieve an IPE outcome of learning how to work with the other professional group.

Table 2. Cohort-specific and combined responses in relation to perceived usefulness of role-plays in IPE.

\begin{tabular}{lcccc}
\hline \multicolumn{4}{c}{ "Role-plays are a useful activity in IPE to learn how to work with the other professional group." } \\
\hline & $\mathbf{2 0 1 7}$ & $\mathbf{2 0 1 8}$ & $\mathbf{2 0 1 9}$ & Ave. score \\
\hline MITS & 4.33 & 4.62 & 4.38 & 4.44 \\
\hline MSW & 4.00 & 4.43 & 4.19 & 4.21 \\
\hline MITS \& MSW & 4.11 & 4.47 & 4.23 & 4.30 \\
\hline
\end{tabular}

Table 2 shows the informants' high level of agreement regarding the perceived usefulness of role-plays as an IPE activity. The levels range from those closer to the grading "agree" for the 2017 session, whereas in 2018 the range overall was between "agree" and "strongly agree". The 2019 figures lie roughly between "agree" and "strongly agree". MITS students recorded higher levels of agreement than MSW students. This may be explained by the fact that all MITS students have an opportunity to role-play, both as an interpreter and as a LOTE-speaking service user.

Among the MSW students, the percentage of those who had role-played once was around $65 \%$. This means that approximately $35 \%$ of MSW students participated as observers only, which is likely to account for the lower level of agreement with the perceived usefulness of role-plays among this cohort. Table 3 presents data on informants' perceived level of knowledge of the other professional group after participation in the IPE session: 
Hlavac, J., \& Saunders, B. (2021). Simulating the context of interpreter-mediated social work interactions via interprofessional education. Linguistica Antverpiensia, New Series: Themes in Translation Studies, 20, 186-208.

Table 3. Cohort-specific and combined responses in relation to perceived change in level of knowledge of the other professional group.

\begin{tabular}{lcccc}
\hline \multicolumn{5}{c}{ "My knowledge of how to work with professionals from the other group has increased." } \\
\hline & $\mathbf{2 0 1 7}$ & $\mathbf{2 0 1 8}$ & $\mathbf{2 0 1 9}$ & Ave. score \\
\hline MITS & 4.20 & 4.56 & 4.58 & 4.47 \\
\hline MSW & 4.07 & 4.30 & 4.22 & 4.20 \\
\hline MITS \& MSW & 4.11 & 4.35 & 4.27 & 4.26 \\
\hline
\end{tabular}

Table 3 shows that students from both cohorts generally agree that their knowledge of the other professional group increased as a result of the IPE session. Slightly higher degrees of agreement are recorded among the MITS students compared to the MSW students, but no cohort or any year group has a level of response that, in overall terms, is below that of "I agree" to the above statement.

Table 4. Combined and cohort-specific responses in relation to perceived change in level of knowledge of one's own professional group.

\begin{tabular}{lcccc}
\hline \multicolumn{4}{c}{ "My knowledge of how professionals in my own discipline work has increased." } \\
\hline & $\mathbf{2 0 1 7}$ & $\mathbf{2 0 1 8}$ & $\mathbf{2 0 1 9}$ & Ave. score \\
\hline MITS only & 4.27 & 4.44 & 4.08 & 4.26 \\
\hline MSW only & 3.79 & 4.11 & 4.00 & 3.97 \\
\hline MITS \& MSW & 3.95 & 4.17 & 4.01 & 4.04 \\
\hline
\end{tabular}

Table 4 shows that students from both cohorts generally agree that their knowledge of their own professional group increased as a result of the IPE session. Again, slightly higher degrees of agreement are recorded among MITS students compared to MSW students, but all responses are on average just above or just below the grading of "Agree". Comparing Table 3 with Table 4, we see that the informants record a slightly higher increase in knowledge of the other group compared to their own. This is to be expected, because the differentiating feature of the IPE session is interaction with students from the other disciplinary cohort with whom the informants have had little or no previous contact.

Table 5 presents data relating to the informants' perceived increase in skills in relation to the service user with LEP:

Table 5. Combined and cohort-specific responses in relation to perceived change in skill level beneficial to the service user with LEP.

"The joint session has given me skills that, when employed, will be of benefit to the service user with LEP."

\begin{tabular}{lcccc}
\hline & $\mathbf{2 0 1 7}$ & $\mathbf{2 0 1 8}$ & $\mathbf{2 0 1 9}$ & Ave. score \\
\hline MITS only & 4.33 & 4.47 & 4.42 & 4.41 \\
\hline MSW only & 4.03 & 4.28 & 4.16 & 4.17 \\
\hline MITS \& MSW & 4.14 & 4.32 & 4.19 & 4.25 \\
\hline
\end{tabular}

Table 5 presents the informants' perceptions in relation to how skills acquired in the IPE session might benefit service users with LEP. The informants were required to interpret "benefit" themselves, as it was not defined. The statement could apply to: 
Hlavac, J., \& Saunders, B. (2021). Simulating the context of interpreter-mediated social work interactions via interprofessional education. Linguistica Antverpiensia, New Series: Themes in Translation Studies, 20, 186-208.

- procedural - both interpreter and social worker introducing themselves to the LEP service user;

- situational - exchanging eye contact with the LEP service user, attending to turn-taking and refraining from overlapping so that the service user is able to interact freely with others, directly address the social worker and receive interpretations of all others' utterances;

- discourse-rhetorical - the way that spoken and non-verbal messages are conveyed to and received from the service user with LEP, including the relational messages such as "ice-breakers", "small talk", affect and intonational or paralinguistic markers present in all source speakers' speech.

All the informants recorded "agree" or "strongly agree" to this statement. The responses are very similar to those given in Table 4, which suggests that the informants felt that their enhanced knowledge of how to work with an LEP service-user is as high as their perceived increase in knowledge about the other professional group.

It was assumed that for many MSW students the IPE session was the first occasion they had had to interact with a service user using LOTE (albeit in a simulated situation). We therefore anticipated that the MSW cohort would record a level of perceived skill acquisition beneficial to the LEP service user that was higher than that recorded among the MITS students. This is because MITS students regularly practise interacting with LOTE-speakers in role-plays as part of their weekly workshops. It was therefore assumed that MITS students would have a high pre-session perceived level of skill in working with LOTE-speakers that would not increase appreciably as a result of the IPE session. While the MITS students regularly play the role of a service user with LEP in weekly dialogue interpreting workshops where they alternate LOTEspeaker, English-speaker and interpreter roles with classmates, this LOTE-simulated role is rarely available to MSW students. Indeed, the MITS students recorded greater agreement with the statement than the MSW students, perhaps because all of the MITS students also played the role of the service user with LEP in one of the role-plays. Through their enactment of this role, it appears that they felt that their skills levels had improved to a greater extent than those interlocutors who do not take on that role - the MSW students. Of relevance here is that up to a third of the MSW students did not have an opportunity to role-play the social worker and were observers only for both role-play sessions.

Data on the pre- and post-interactional activities are presented below. The informants were requested to answer a question with an affirmative or a negative response and then to provide a short explanation for their response. Table 6 presents the informants' yes and no responses only. 
Hlavac, J., \& Saunders, B. (2021). Simulating the context of interpreter-mediated social work interactions via interprofessional education. Linguistica Antverpiensia, New Series: Themes in Translation Studies, 20, 186-208.

Table 6. Cohort-specific and combined responses in relation to the usefulness of pre- and postinteractional exchanges

\begin{tabular}{|c|c|c|c|c|c|c|c|c|c|c|c|c|c|c|c|c|}
\hline & \multicolumn{16}{|c|}{ "Do you think a briefing beforehand and a debriefing afterwards are useful?" } \\
\hline & \multicolumn{4}{|c|}{2017} & \multicolumn{4}{|c|}{2018} & \multicolumn{4}{|c|}{2019} & \multicolumn{4}{|c|}{ Total } \\
\hline & $\stackrel{\varrho}{\rightleftharpoons}$ & 2 & $\frac{\pi}{z}$ & $\begin{array}{l}\bar{\pi} \\
0 \\
0\end{array}$ & $\stackrel{\varrho}{>}$ & 운 & $\frac{\pi}{z}$ & $\begin{array}{l}\bar{\pi} \\
0 \\
0\end{array}$ & $\stackrel{\check{\varrho}}{\nu}$ & 2 & $\frac{\varangle}{z}$ & 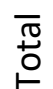 & $\stackrel{\varrho}{>}$ & 2 & $\frac{\varangle}{z}$ & $\begin{array}{l}\bar{\pi} \\
\stackrel{0}{0} \\
0\end{array}$ \\
\hline MITS & 14 & 1 & 0 & 15 & 16 & 0 & 0 & 16 & 11 & 0 & 1 & 12 & 41 & 1 & 1 & 43 \\
\hline MSW & 25 & 1 & 3 & 29 & 60 & 3 & 3 & 66 & 74 & 0 & 6 & 80 & 159 & 4 & 12 & 175 \\
\hline $\begin{array}{l}\text { MITS \& } \\
\text { MSW }\end{array}$ & 39 & 2 & 3 & 44 & 76 & 3 & 3 & 82 & 85 & 0 & 7 & 92 & 200 & 5 & 13 & 218 \\
\hline
\end{tabular}

Table 6 shows that the students overwhelmingly agreed that the briefing and the debriefing were useful. For MITS students, both a briefing and a debriefing are features that are taught to them as industry standards (CEH, 2014; CMY, 2011), enabling interpreters to work effectively with others. The briefing allows the interpreter and the social worker to touch base on the general purpose or format of the interaction, whether it is the social worker's first encounter with the service user, the number of people present, any diagnostic tools or information forms that the social worker may be using, concerns about safety (if relevant), seating arrangements and mode of interpreting. Furthermore, the briefing allows the social worker to emphasise how they wish to commence the interaction, such as opening it themself in English, introducing the interpreter - with this then interpreted into LOTE by the interpreter.

The briefing serves the social worker's needs, enabling them to discuss at least the above points. It also enables them to mention the service user's speech or behavioural features, their previous experience with interpreters, and cultural factors (where the nature of the interaction may be less familiar or performed in a different way), so that the social worker can decide to minimise the coverage of some points that the interpreter foresees could result in a misunderstanding or a miscommunication.

Selected MITS and MSW students' comments representative of the full sample are noted to illustrate the themes derived from the recurrent responses. All the comments below relate to affirmative responses unless noted as accompanying a negative response. They are identified only by the year of the cohort. Below are comments from MITS students in relation to a preinteractional briefing:

Opportunity for all parties to consider expectations, roles and socio-cultural information as well as ethical questions:

The basic background of the client; what the social worker is going to do with the client; what should an interpreter specifically pay attention to. (2018)

To know which aspect of SW [social work] it is; who the client is. (2018)

It is helpful for the interpreter to know what the purpose of the interaction is so that they are aware where the conversation is going. (2017)

So we can know each other's roles and responsibilities. (2019) 
Hlavac, J., \& Saunders, B. (2021). Simulating the context of interpreter-mediated social work interactions via interprofessional education. Linguistica Antverpiensia, New Series: Themes in Translation Studies, 20, 186-208.

Pre-empt emotionally confronting situations or those with safety concerns:

Are there going to be sensitive or personal questions asked? (2018)

If it is known that the client has violent tendencies or is particularly sensitive about certain issues, the interpreter should be notified. (2018)

Pre-empt language issues for both the interpreter and the social worker:

Requesting information on any specialist language or terms to be used. (2017)

Know the situation, can prepare and anticipate the questions that could be asked. (2018)

The only MITS student to give a "no" response made the following comment:

Things change all the time, especially when social workers themselves have no preparation for the counselling ... (2017)

The following are selected comments from MITS students in relation to a post-interactional debriefing:

Debriefing gives us the chance to reflect on what worked well and what did not. It's a chance for self-reflection ... (2017)

What was not conveyed, i.e., what needs to be discussed/conveyed for the next meeting, if relevant. (2018)

A debriefing will let the interpreter know what to improve on. (2018)

I could get objective feedback and deepen my knowledge of social work. (2019)

Being able to reflect on what happened is important because thinking it over after will help people realise what they could've done better. Having other opinions is also important. (2019)

The comments from the MITS students about the briefing relate to the following features, shown here in bullet points:

- situational - specific area of social work that the interaction relates to and its purpose;

- security and trauma avoidance - forewarning of distressing content as a way to minimise primary or secondary stress, available information on service users' previous violence or distress;

- coordination of talk - question type, elicitation techniques, sensitive content;

- linguistic - terms and jargon.

As stated, most of these features are identified in guideline documents that advocate a briefing between a social care professional and an interpreter (CMY, 2011; DHHS, 2018).

The MITS students' comments above suggest that a debriefing can enable the following outcomes, shown here in bullet points:

- the ability to draw attention to the non-transfer of content or other information, that is, the interpreter can report on what they were not able to convey either from or to the social worker; 
Hlavac, J., \& Saunders, B. (2021). Simulating the context of interpreter-mediated social work interactions via interprofessional education. Linguistica Antverpiensia, New Series: Themes in Translation Studies, 20, 186-208.

- the ability to report on non-verbal signals whose meaning may not have been conveyed to the social worker;

- a dual-perspective reflection - voicing one's own view of how an interaction proceeded and hearing the view of the social worker;

- a reflection or discussion which can be conducive to self-evaluation and selfimprovement strategies; and

- increased content knowledge - checking or eliciting information on social work procedures and terms.

There were a much larger number of MSW informants' comments, which are thematically presented:

The briefing enables all parties to consider expectations, roles and socio-cultural as well as ethical questions:

A briefing is needed in relation to the client's culture, background, reasons for attending the session ... (2017)

Cultural imperative issues - is looking in the eyes okay? How to ask about health issues and to take responses with a grain of salt - interpreters are not cultural experts. (2018)

Revisit confidentiality and introduce roles. (2018).

Clarify situation, mental preparation, consider personal or inner conflicts with issues. (2018)

Provided insight into how my questions are conveyed culturally and how best to interact with clients. (2018)

Important for both social worker and interpreter to mutually agree on protocols or raising issues if things happen not according to the plan. (2018)

Pre-empt emotionally confronting situations or those with safety concerns:

A briefing can help provide a chance to ... avoid surprises. (2018)

The possibility that the client may harm others or swear. (2018)

Pre-empt situational, relational features:

[The briefing] allowed us to learn about eye contact and gestures. (2018)

We talked about feeling strange that the social worker talks with the client directly, without looking at the interpreter. (2019)

Pre-empt language issues for both social worker and interpreter:

Clarify some terms ... especially how to express feeling and empathy in the language. (2018)

Legal terms, health terms, abbreviations we may use. (2018)

One of the few MSW students who answered "no" made the following observation:

Briefing may clarify what is to be discussed. But it may also bias the interpreter before the session. It may not be necessary if the interpreter is solely there to translate/interpret. (2018) 
Hlavac, J., \& Saunders, B. (2021). Simulating the context of interpreter-mediated social work interactions via interprofessional education. Linguistica Antverpiensia, New Series: Themes in Translation Studies, 20, 186-208.

The following comments were recorded in relation to the debriefing:

\section{General review:}

It allows students to assess earlier expectations. (2018)

A debriefing for summary could make sure there's no misunderstanding between the client and the social worker. (2017)

A debriefing will provide a chance to check if any concerns have been raised by the session. (2019)

Clarify certain things in the interview, such as intonation of the clients, and give/receive feedback. (2017)

Ensure that you know that everything was interpreted correctly. (2018)

Identifying things to be avoided in general or in future interactions:

Clarify what worked/what went wrong, also potential for dangerous situations. (2018)

To prevent burnout and clarify some body language or information that was not verbally spoken. (May 2018)

Regarding the briefing, the comments from the MSW students can be surmised as encompassing the following, shown here in bullet points:

- provide an opportunity to consider the interaction's purpose and context;

- gain information about the service user's cultural background, customary forms of communication (greetings, eye contact, body language) as well as the overall structure of the communication (pre-empting how an initial meeting dealing with family violence is approached);

- clarify the role-relationship and discussion whether the interpreter should or ought not to intervene (for specific reasons), or if there appears to be miscommunication or even a communication breakdown between the social worker and the LEP service user (cf. Sawrikar, 2015);

- alert the interpreter to the possibility that the interaction may be emotionally charged or compromise their personal safety; and

- pre-empt specialist terms to be used and information on how empathy or rapport is signaled and acknowledged in the LOTE (cf. Sawrikar, 2015).

The MSW students' comments on the debriefing suggest that they see this as an opportunity to review many points mentioned in relation to the briefing, similarly to Freed's (1988) observations.

\section{Conclusion}

This article outlined and discussed the outcomes to three research questions regarding the desired IPE session learning outcomes, including enhanced knowledge of the other professional group's profile and perspective; enhanced insight into the direct practice role of a professional from students' own groups; an enhanced understanding of how to work 
Hlavac, J., \& Saunders, B. (2021). Simulating the context of interpreter-mediated social work interactions via interprofessional education. Linguistica Antverpiensia, New Series: Themes in Translation Studies, 20, 186-208.

effectively with LEP service users, and an enhanced appreciation of the role of pre-session briefings and post-session debriefings.

Our research affirmed the usefulness of role-plays as the main component of IPE, that is, as a means of acquiring other skills or knowledge bases rather than as a learning outcome in their own right. The responses from 218 informants from both disciplines over three years revealed widespread agreement on this point. Our research also revealed that learners from both professional groups and all year groups acquired enhanced knowledge of the other group, their own group and LEP service users. The levels of agreement were slightly higher for the other group and for LEP services users than for the participants' own group. Slight differences in the levels of agreement also existed for those whose level of role-play involvement was higher (i.e., all MITS students). These positive results conform to fundamental or "generic" goals that underpin IPE learning, regardless of the discipline area, to modify "attitudes/perceptions (changes in reciprocal attitudes or perceptions between participant groups)" and to acquire "knowledge/skills (gains of knowledge and skills linked to interprofessional collaboration)" (Barr et al., 2005, p. 43).

Finally, our research revealed the usefulness of students' pre-interactional and postinteractional activities that are not only industry standards but situational necessities for both interpreters and social workers. For interpreters, there is usually a larger deficit in information, as it is the social workers who are typically the "custodians" of most of the information relating to the interaction. But for social workers also, responses suggest that the pre-interactional briefing allowed them to consider their own expectations of a mediated interaction and the role of the interpreter, and also to discuss protocols for (self) introductions, interventions by the interpreter, plus cultural, ethical and safety-based issues. Context-specific knowledge, the use and meaning of specialist terms and discourse-pragmatic features were also topics discussed in both briefings and debriefings.

While IPE sessions require considerable organisational and pedagogic investment, learners' responses suggest that participation results in high levels of agreement that learners broaden their understanding and knowledge of the other professional group and feel better equipped to interact with professionals from that group in a collaborative and effective way. A desirable follow-up study would be to track MITS and MSW graduates to elicit data on their experiences of working with the other professional groups in "real-life" settings, and the contribution that the IPE sessions made towards these. 
Hlavac, J., \& Saunders, B. (2021). Simulating the context of interpreter-mediated social work interactions via interprofessional education. Linguistica Antverpiensia, New Series: Themes in Translation Studies, 20, 186-208.

\section{Appendices}

\section{Appendix 1}

Role-play instructions for LOTE-speaker with LEP who has experienced family violence:

Role: You are a mother of two who has recently experienced family violence. You and your children are currently living in emergency accommodation. You have a part-time retail job and your children attend primary school. You and your children are no longer in contact with the children's biological father.

Context: Your current partner has been acting violently towards you. However, you have been unwilling to take out a family violence intervention order against your current partner. Child Protection has been involved with your family for the last 12 months and there is now a child protection order in place. The order has the condition that you must not expose your children to family violence. However, the order did not stipulate that your current partner was not allowed to live with you and to remain in the home.

Function/Purpose: You are concerned that your children will be taken from you after this last incident of violence perpetrated by your current partner against you. The child protection worker will be interviewing you and will be going through a number of things about your situation and whether your children are continuing to be exposed to violence. If so, the child protection worker will ask you a number of questions that could relate to the issuing of an intervention order against your current partner. You are suffering greatly due to the violence perpetrated by your current partner but are apprehensive about an order being issued that would restrict your current partner living from you. The reason for this is that you are partially financially dependent on your current partner.

\section{Appendix 2}

Role-play instructions for social worker working with a LOTE-speaker with LEP who has experienced family violence:

Role: You are a child protection worker in a family violence service.

Context: You are a DHS (Dept. of Human Services) child protection worker, interviewing a LOTE-speaking female victim of domestic violence with LEP who is currently living in emergency accommodation with her two children. As the social worker, you are required to elicit further information about the nature of the violence to which the victim has been subjected.

Function/Purpose: You need to follow normal protocols for the eliciting of information, and gather the following:

- Current type of housing and type of preferred housing

http://www.housing.vic.gov.au/community-housing

- Date of arrival in Australia 
Hlavac, J., \& Saunders, B. (2021). Simulating the context of interpreter-mediated social work interactions via interprofessional education. Linguistica Antverpiensia, New Series: Themes in Translation Studies, 20, 186-208.

- Ethnicity/cultural identity

- Date separated from husband/partner

- Any known forms of disability

- Perpetrator's name, aliases, current address, place of work, ethnic/cultural identity, language/s spoken, known disabilities

- Details on children: currently with victim; children were witnesses/victims to violence, counselling services for children? Need for Child Protection Services to be involved.

- Family violence experienced:

- Date/s, instances of the following: physical abuse, sexual abuse, financial abuse, emotional abuse, social abuse, verbal abuse, other forms of abuse

- Risk indicators: pregnancy/new birth, depression, mental health issues, drug/alcohol misuse, verbalisation of suicidal thoughts

- Intervention order? Police involvement, court hearings?

- Safe times to further contact victim 
Hlavac, J., \& Saunders, B. (2021). Simulating the context of interpreter-mediated social work interactions via interprofessional education. Linguistica Antverpiensia, New Series: Themes in Translation Studies, 20, 186-208.

\section{References}

AASW [Australian Association of Social Workers]. (2019). Australian social work education and accreditation standards. https://www.aasw.asn.au/document/item/12753

Abramovitz, M. (1998). Social work and social reform: An arena of struggle. Social Work, 43(6), 512526. https://doi.org/10.1093/sw/43.6.512

AUSIT [Australian Institute of Interpreters and Translators]. (2006). Guidelines for health professionals working with interpreters. https://ausit.org/wp-content/uploads/2020/02/AUSIT-Guidelines For Health Professionals-working-with-Interps.pdf

Baker, R., \& Briggs, J. (1975). Working with interpreters in social work practice. Australian Social Work, 28(4), 31-37. https://doi.org/10.1080/03124077508549453

Bancroft, M. A. (2015). Community interpreting: A profession rooted in social justice. In H. Mikkelson \& R. Jourdenais (Eds.), The Routledge handbook of interpreting (pp. 217-235). Routledge. https://doi.org/10.1075/intp.1.1.08mik

Banks, S. (2004). Professional integrity, social work and the ethics of distrust. Social Work and Social Sciences Review, 11(2), 20-35.

Barr, H., Koppel, I., Reeves, S., Hammick, M., \& Freeth, D. (2005). Effective interprofessional education: Argument, assumption and evidence. Blackwell. https://doi.org/10.1002/9780470776445

Ben-Ari, A., \& Strier, R. (2010). Rethinking cultural competence: What can we learn from Levinas? British Journal of Social Work, 40(7), 2155-2167. https://doi.org/10.1093/bjsw/bcp153

Berthold, S. M., \& Fischman, Y. (2014). Social work with trauma survivors: Collaboration with interpreters. Social work, 59(2), 103-110. https://doi.org/10.1093/sw/swu011

Brämberg, E. B., \& Sandman, L. (2012). Communication through in-person interpreters: A qualitative study of home care providers' and social workers' views. Journal of Clinical Nursing, 22(1-2), 159-167. https://doi.org/10.1111/j.1365-2702.2012.04312.x

Buring, S. M., Bhushan, A., Broeseker, A., Conway, S., Duncan-Hewitt, W., Hansen, L., \& Westberg, S. (2009). Interprofessional education: Definitions, student competencies, and guidelines for implementation. American Journal of Pharmaceutical Education, 73(4).

CEH [Centre for Culture, Ethnicity and Health]. (2014). Booking and briefing an interpreter. https://www.ceh.org.au/wp-content/uploads/2015/12/LS3 Booking-and-briefing-an-inter preter.pdf

Chand, A. (2005). So you speak English?: Language barriers in child protection social work with minority ethnic families. British Journal of Social Work, 35(6), 807-821. https://doi.org/10.10 93/bjsw/bch205

CMY [Centre for Multicultural Youth]. (2011). Good practice guide: Working with interpreters. https://www.cmy.net.au/resource/working-with-interpreters-2/

Cooper, H., Carlisle, C., Gibbs, T., \& Watkins, C. (2001). Developing an evidence base for interdisciplinary learning: A systematic review. Journal of Advanced Nursing, 35(2), 228-237. https://doi.org/10.1046/j.1365-2648.2001.01840.x

Corsellis, A. (2008). Public service interpreting: The first steps. Palgrave Macmillan. https://doi.org/10. $1057 / 9780230581951$

DHHS [Department of Health and Human Services]. (2018). How to work with interpreters and translators: A guide to effectively using language services. https://www.dhhs.vic.gov.au/howwork-interpreting-and-translating-services

Dubus, N. (2015). Using an interpreter as a co-facilitator. Social Work with Groups, 38(1), 44-55. https://doi.org/10.1080/01609513.2014.931670

Freed, A. O. (1988). Interviewing through an interpreter. Social Work, 33(4), 315-319. https://doi.org/ $10.1093 / \mathrm{sw} / 33.4 .315$ 
Hlavac, J., \& Saunders, B. (2021). Simulating the context of interpreter-mediated social work interactions via interprofessional education. Linguistica Antverpiensia, New Series: Themes in Translation Studies, 20, 186-208.

Frey, R., Roberts-Smith, L., \& Bessel-Browne, S. (1990). Working with interpreters in law, health and social work. National Accreditation Authority for Translators and Interpreters.

Glasser, I. (1983). Guidelines for using an interpreter in social work. Child Welfare, 62(5), 468-470.

Hale, S. B. (2007). Community interpreting. Palgrave Macmillan. https://doi.org/10.1057/9780230593 $\underline{442}$

Hale, S., \& Napier, J. (2013). Research methods in interpreting: A practical resource. Bloomsbury.

Hlavac, J., Gentile, A., Orlando, M., Zucchi, E., \& Pappas, A. (2018). Translation as a sub-set of public and social policy and a consequence of multiculturalism: The provision of translation and interpreting services in Australia. International Journal of the Sociology of Language, 251, 5588. https://doi.org/10.1515/ijsl-2018-0004

Humphreys, C., Atkar, S., \& Baldwin, N. (1999). Discrimination in child protection work: Recurring themes in work with Asian families. Child and Family Social Work, 4(4), 283-291. https://doi. org/10.1046/j.1365-2206.1999.00132.x

JCCD [Judicial Council on Cultural Diversity] (2017). Recommended National Standards for Working with Interpreters in Courts and Tribunals. http://www.jccd.org.au/wp-content/uploads/2018/ 02/JCCD-Interpreter-Standards.pdf

Jones, M. (1985). The community interpreter: A special case. Australian Social Work, 38(3), 35-38. https://doi.org/10.1080/03124078508549869

Krystallidou, D., Van De Walle, C., Deveugele, M., Dougali, E., Mertens, F., Truwant, A., Van Praet, E., \& Pype, P. (2018). Training "doctor-minded" interpreters and "interpreter-minded" doctors: The benefits of collaborative practice in interpreter training. Interpreting, 20(1), 126-144. https://doi.org/10.1075/intp.00005.kry

Lannoy, K., \& Van Gucht, J. (2006). Babel rebuilt: A survey of social welfare institutions and interpreting and translation services in Flanders. In A. Pym, M. Shlesinger, \& Z. Jettmarová (Eds.), Sociocultural aspects of translating and interpreting (pp. 191-200). John Benjamins. https:// doi.org/10.1075/btl.67.24lan

Ozolins, U. (2013). Role playing pumpkin. In C. Schäffner, K. Kredens, \& Y. Fowler (Eds.), Interpreting in a changing landscaping: Selected papers from Critical Link 6 (pp. 31-43). John Benjamins. https://doi.org/10.1075/btl.109.05ozo

Pöchhacker, F. (2006). Going social?: On the pathways and paradigms in interpreting studies. In A. Pym, M. Shlesinger, \& Z. Jettmarová (Eds.), Sociocultural aspects of translating and interpreting. (pp. 215-232). John Benjamins. https://doi.org/10.1075/btl.67.27poc

Pöllabauer, S. (2012). Gatekeeping practices in interpreted social service encounters. Meta, 57(1), 213-234. https://doi.org/10.7202/1012750ar

Rubin, A., \& Babbie, E. (2011). Research methods for social work. Brooks/Cole.

Sawrikar, P. (2015). How effective do families of non-English-speaking background (NESB) and child protection caseworkers in Australia see the use of interpreters?: A qualitative study to help inform good practice principles. Child \& Family Social Work, 20(4), 396-406. https://doi.org/ $10.1111 / \mathrm{cfs} .12088$

Stuart, P. (2013). Social work profession: History. In T. Mizrahi \& L. E. Davis (Eds.), Encyclopedia of social work (pp. 1-15). National Association of Social Workers Press and Oxford University Press. https://doi.org/10.1093/acrefore/9780199975839.013.623

Tipton, R. (2016). Perceptions of the occupational other: Interpreters, social workers and intercultures. British Journal of Social Work, 46(2), 463-479. https://doi.org/10.1093/bjsw/ $\underline{\text { bcu136 }}$

Tipton, R., \& Furmanek, O. (2016). Dialogue interpreting: A guide to interpreting in public services and the community. Routledge. https://doi.org/10.4324/9781315644578-14 
Hlavac, J., \& Saunders, B. (2021). Simulating the context of interpreter-mediated social work interactions via interprofessional education. Linguistica Antverpiensia, New Series: Themes in Translation Studies, 20, 186-208.

Tobias, S., Hlavac, J., Sundin, L., \& Avella Archila, A. (2020). Identifying gaps in professional development opportunities for translators and interpreters in Australia. https://www.monash. edu/ data/assets/pdf file/0016/2210227/Identifying-Gaps-in-PD-Opportunities-1.pdf

Tribe, R., \& Raval, H. (2002). Working with interpreters in mental health. Routledge.

Tribe, R., \& Morrissey, J. (2004). Good practice issues in working with interpreters in mental health. Intervention, 2(2), 129-142.

Turner, F. (1990). Interpreters and social workers: Contemporary professional challenges. In D. Bowen \& M. Bowen (Eds.), Interpreting: Yesterday, today and tomorrow (pp. 122-130). John Benjamins. https://doi.org/10.1075/ata.iv.22tur

Van der Haar, M. (2007). Ma(r)king differences in Dutch social work: Professional discourse and ways of relating to clients in context. Dutch University Press.

VTPU [Victorian Transcultural Psychiatry Unit]. (2006, July). Guidelines for working effectively with interpreters in mental health settings. https://www.imiaweb.org/uploads/pages/812 2..pdf

Westlake, D., \& Jones, R. (2018). Breaking down language barriers: A practice-near study of social work using interpreters. The British Journal of Social Work, 48(5), 1388-1408. https://doi.org/10. $\underline{1093 / \mathrm{bjsw} / \mathrm{bcx} 073}$

\footnotetext{
${ }^{1}$ Monash University Human Research Ethics Committee gave its approval to collect data from human informants: Project no. 5730 - A multi-perspective approach to translation pedagogy and practice (2016-2018); Project no. 21111 - Inter-professional sessions - Interpreting, Medical, Social Work and Nursing students (2019-present).
} 